\title{
Serum levels of hydroxylated PCBs, PCBs and thyroid hormone measures of Japanese pregnant women
}

\author{
Aya Hisada $\cdot$ Kazuhisa Shimodaira $\cdot$ Takashi Okai $\cdot$ Kiyohiko Watanabe $\cdot$ \\ Hiroaki Takemori $\cdot$ Takumi Takasuga $\cdot$ Yumiko Noda $\cdot$ Miyako Shirakawa \\ Nobumasa Kato $\cdot$ Jun Yoshinaga
}

Received: 20 June 2012/ Accepted: 4 September 2012/Published online: 30 September 2012

(C) The Japanese Society for Hygiene 2012

\begin{abstract}
Objectives The purpose of this study was to investigate the associations between serum concentrations of hydroxylated PCBs (OH-PCBs) and PCBs and measures of thyroid hormone status of Japanese pregnant women.

Methods The concentrations of free thyroxine (fT4), thyroid stimulating hormone (TSH), and thyroxine binding globulin (TBG) as well as 16 OH-PCB isomers and 29 PCB isomers were analyzed in the serum of 129 women sampled in the first trimester of gestation. Dietary and lifestyle information of the subjects was obtained by self-administered questionnaire. Multiple regression analysis was performed using measures of thyroid hormones as the dependent variable and serum levels of $\mathrm{OH}-\mathrm{PCB} / \mathrm{PCBs}$, urinary iodine concentration, and other potential covariates (age, BMI, smoking, etc.) as independent variables.

Results Geometric mean (GM) concentration of the sum of 16 isomers of OH-PCBs was $120 \mathrm{pg} / \mathrm{g}$ wet wt. and that
\end{abstract}

A. Hisada $\cdot$ J. Yoshinaga $(\bowtie)$

Department of Environmental Studies,

The University of Tokyo, 5-1-5 Kashiwanoha,

Kashiwa, Chiba 277-8563, Japan

e-mail: junyosh@k.u-tokyo.ac.jp

K. Shimodaira $\cdot$ T. Okai

Department of Obstetrics and Gynecology,

Showa University School of Medicine, 1-5-8 Hatanodai,

Shinagawaku, Tokyo 142-8555, Japan

K. Watanabe $\cdot$ H. Takemori · T. Takasuga

Shimadzu Techno-Research, Inc., \#1 Nishinokyo-Shimoaicho,

Nakakyo-ku, Kyoto 604-8436, Japan

Y. Noda $\cdot$ M. Shirakawa $\cdot$ N. Kato

Department of Psychiatry and Neurology,

Showa University School of Medicine,

1-5-8 Hatanodai, Shinagawaku, Tokyo 142-8555, Japan of 29 isomers of PCBs was $68 \mathrm{ng} / \mathrm{g}$ lipid wt., respectively, in the serum of the subjects. Iodine nutrition was considered adequate to high from urinary iodine level (GM, $370 \mu \mathrm{g} / \mathrm{g}$ creatinine). The mean concentration of TSH, fT4 and TBG was $1.34 \pm 1.37 \mu \mathrm{IU} / \mathrm{mL}, 1.22 \pm 0.16 \mathrm{ng} / \mathrm{dL}$ and $33.0 \pm 6.4 \mu \mathrm{g} / \mathrm{mL}$, respectively, with a small number of subjects who were outside the reference range. Multiple regression analysis revealed that serum concentrations of $\mathrm{OH}-\mathrm{PCB} / \mathrm{PCBs}$ were not significantly associated with any of the measures of thyroid hormone status.

Conclusions Exposure/body burden of $\mathrm{OH}-\mathrm{PCB}$ and PCBs at environmental levels does not have a measurable effect on thyroid hormones.

Keywords Hydroxylated polychlorinated biphenyls . Polychlorinated biphenyls · Thyroid hormone · Urinary iodine $\cdot$ Pregnant woman

\section{Introduction}

Thyroid hormone is essential for normal development of fetal brain [1]. Congenital hypothyroidism, cretinism, causes mental retardation. Maternal thyroid deficiency can also result in abnormal development of newborns. Moreover, Haddow et al. [2] reported that even a mild maternal hypothyroidism adversely affects IQ of her offspring. The first trimester of pregnancy is a critical period for fetal development because the fetus is dependent on maternal thyroid hormone supply during this period $[3,4]$.

Previous studies indicated that prenatal exposure to polychlorinated biphenyls (PCBs) adversely affects children's intelligence and neurobehavioral functions [5]. One of the possible mechanisms for this effect was deteriorated thyroid hormone status caused by the toxic actions of some 
congeners of PCBs [6]. A number of previous in vitro and in vivo studies on the effect of PCBs on thyroid hormone status suggested several mechanisms of action [7]. There are also a number of human studies which were carried out to see if association was found between thyroid hormone status and exposure to PCBs, however, the results were inconsistent across the studies [8, 9].

There were also indications that hydroxylated metabolites of PCBs, OH-PCBs, can impair thyroid hormone function; it is reported that $\mathrm{OH}-\mathrm{PCB}$ s have stronger affinity to thyroid hormone transporter protein than the natural ligand (T4) and PCBs [10], and that OH-PCBs can inhibit sulfotransferase activity for the conjugation of thyroid hormone [11]. However, the number of human studies on the association between $\mathrm{OH}-\mathrm{PCB}$ s exposure and thyroid hormone status is much more limited than that on PCBsthyroid relationship [12-17]. It is, therefore, the aim of this study to see if exposure to OH-PCB affects thyroid hormone status of pregnant women taking its relevance to developmental effect of offspring into consideration.

Iodine, the essential component of thyroid hormone, is indispensable for neurodevelopment [18], and Dallaire et al. $[16,19]$ pointed out that iodine intake could be one of the possible modifying factors of PCBs-thyroid hormone relationship. However, there are only two studies that examined thyroid effect of PCBs exposure while taking iodine nutritional status into consideration [20, 21]. The Japanese are generally considered iodine-adequate, or even excessive, due to habitual consumption of iodine rich foods, such as seaweed and fish. Not only iodine deficiency but also iodine excess can affect thyroid function [22]. Thus, in this study we assessed iodine status of subjects as a potential covariate of the association between $\mathrm{OH}-\mathrm{PCB}$ and PCBs exposure and thyroid hormone status.

\section{Subjects and methods}

\section{Participants}

One hundred and twenty-nine pregnant women of 10-12 gestational weeks were recruited at a university hospital in Tokyo during the period 2009-2011. The criteria for eligibility was that the woman was of reproductive age (20-50), lived in Tokyo Metropolitan Area, and had no known diseases that could affect normal thyroid function. The hospital Ethics Committee approved the research and all mothers gave written informed consent prior their inclusion.

\section{Sampling}

Blood and urine were sampled from the subject at one of the regular health checks during the first trimester. Blood was taken without anticoagulant and serum was recovered into a polypropylene (PP) tube immediately after sampling. The urine sample was taken by the subject herself in a paper cup and an aliquot was dispensed into several PP tubes. The PP tube was washed with ultrapure water and methanol (for HPLC use, Kanto Chemical Co. Ltd., Tokyo) prior to use. Serum and urine samples were stored at $-20{ }^{\circ} \mathrm{C}$. Maternal obstetrical information was obtained from medical records. Dietary and lifestyle information (district of residence, frequency of alcohol drinking and dining out, frequency of seaweed, fish, meat, milk, egg, bean, vegetable and fruits intake) was collected by a selfadministered questionnaire.

Thyroid hormone analyses

Thyroid stimulating hormone (TSH) and free thyroxine (fT4) concentrations in serum was determined by electrochemiluminescence immunoassay (ECLIA) with a commercial kit (ECLusys TSH, fT4, Roche, Japan) and thyroxine binding globulin (TBG) concentration was determined by radioimmunoassay (RIA) with a commercial kit (RIA-gnost TBG, CIS Bio International, France) at a commercial laboratory (SRL Co. Inc., Tokyo, Japan). Reproducibility of the measurement of fT4, TSH and TBG in this laboratory was 3.5, 2.0 and $4.4 \%$, respectively. Reference range for fT4, TSH and TBG in this laboratory is $0.90-1.70 \mathrm{ng} / \mathrm{dL}, 0.500-5.00 \mu \mathrm{IU} / \mathrm{mL}$ and $12-30 \mathrm{mg} / \mathrm{dL}$, respectively.

\section{PCBs and $\mathrm{OH}-\mathrm{PCB}$ s analyses}

Serum concentrations of $\mathrm{OH}-\mathrm{PCB}$ and $\mathrm{PCBs}$ were determined according to Takasuga et al. [23]. In brief, a serum sample $(1 \mathrm{~mL})$ was extracted in dichloromethane under acidic conditions after the addition of ${ }^{13} \mathrm{C}$-labelled $\mathrm{OH}-\mathrm{PCB}$ and ${ }^{13} \mathrm{C}$-labelled PCBs as internal standard. The dichloromethane was passed through a silicagel column and PCBs and $\mathrm{OH}-\mathrm{PCB}$ s fractions were eluted with hexane and acetone, respectively. The acetone fraction was treated with diethyl sulfate and ethylated $\mathrm{OH}-\mathrm{PCB}$ s were extracted into hexane. The two hexane extracts was individually cleaned up by Florisil column chromatography, which was packed with $22 \% \mathrm{H}_{2} \mathrm{SO}_{4}$-silicagel and $44 \% \mathrm{H}_{2} \mathrm{SO}_{4}-$ silicagel. Twenty-nine isomers of PCB (IUPAC number: CB-28, 74, 66, 101, 99, 118, 105, 146, 153, 137, 164/163, 138, 167, 156, 178, 182/187,183, 177, 172, 180, 193, 170, 190, 202, 199, 203, 194, 206 and 209) and penta, hexa and hepta OH-PCB isomers [OH-PeCB isomer A (unknown isomer), 4'-OH-CB120, 3-OH-CB118, 4-OH-CB107, $\mathrm{OH}-\mathrm{PeCB}$ isomers B, OH-HxCB isomer A, $4^{\prime}-\mathrm{OH}-\mathrm{CB} 165 / 3-$ OH-CB153, 4-OH-CB146, 3'-OH-CB138, 4'-OH-CB130, $4^{\prime}$-OH-CB159, OH-HxCB isomers $\mathrm{B}, \mathrm{OH}-\mathrm{HpCB}$ isomer $\mathrm{A}$, 
4-OH-CB187, OH-HpCB isomers B, 4'-OH-CB172] were analyzed using a gas chromatograph (HP 6890, Agilent Technologies, CA, USA) coupled with a high resolution mass spectrometer (Micromass Autospec Ultima, Waters, Milford, MA, USA). A capillary column, DB-5MS [60 m $\times 0.32 \mathrm{~mm}$ I.D. $(0.25 \mu \mathrm{m}), \mathrm{J} \& \mathrm{~W}$, Agilent Technologies, CA, USA] was used for separation of OH-PCBs and HT8-PCB $(60 \mathrm{~m} \times 0.25 \mathrm{~mm}$ I.D., Kanto Chemical Co., Inc., Tokyo, Japan) was for PCBs. The detection limit in serum was $0.6 \mathrm{pg} / \mathrm{g}$ wet wt. for $\mathrm{OH}-\mathrm{PCBs}$ and PCBs. Recovery of internal standards was $83 \pm 10$ and $70 \pm 19 \%$ for PCBs and OH-PCBs, respectively. PCBs concentrations were corrected by serum concentration of total lipid and expressed as ng PCB/g lipid. Total lipid concentration in serum was calculated using the summation method by Akins et al. [24].

Iodine analysis

Iodine concentration in urine was measured using inductively coupled plasma mass spectrometry (ICP-MS) according to a previously published method [25]. The urine sample $(200 \mu \mathrm{L})$ was diluted with $9.7 \mathrm{~mL}$ of $2.5 \%$ tetramethylammonium hydroxide (TMAH) (TAMAPURE-AA TMAH, Tama Chemicals Co., Ltd., Kawasaki, Japan) and $0.1 \mathrm{~mL}$ of $100 \mathrm{ng} / \mathrm{mL}$ tellurium for internal standardization. The sample was filtered through a syringe filter (pore size $0.45 \mu \mathrm{m}$ ) (Minisart; Sartorius Stedim Biotech, Goettingen, Germany) prior to measurement. The iodine and tellurium ions were monitored at $\mathrm{m} / \mathrm{z}=127$ and $\mathrm{m} / \mathrm{z}=130$, respectively, by ICP-MS (Agilent 7500ce, Agilent Technologies Japan, Ltd., Tokyo, Japan). The concentration of iodine was corrected by creatinine concentration, which was determined by a commercial kit (LabAssay ${ }^{\mathrm{TM}}$ Creatinine, Wako Pure Chemical Industries, Ltd., Osaka, Japan) based on the Jaffe method. The detection limit of iodine was $3 \mu \mathrm{g} / \mathrm{L}$. Accuracy of iodine analysis was checked by using urine reference material (RM) (Seronorm Urine Blank, SERO AS, Billingstad, Norway). The mean and standard deviation of triplicate measurement was $144 \pm 3 \mu \mathrm{g} / \mathrm{L}$, which was in agreement with the assigned range of the RM (131-147 $\mu \mathrm{g} / \mathrm{L})$.

\section{Statistical analyses}

Statistical analyses were performed using SPSS for Windows version 12.0 (SPSS Japan Inc., Tokyo, Japan). Normality of distribution was assessed by the Shapiro-Wilkes test. Serum fT4, TSH, OH-PCBs and PCBs concentrations and urinary iodine concentration was log-transformed for statistical analysis.

The association between the concentrations of thyroid hormones measures and $\mathrm{OH}-\mathrm{PCB}$ or $\mathrm{PCB}$ was assessed by a multiple regression analysis. One of the measures of thyroid functions (fT4, TSH or TBG) was used as the dependent variable and the serum concentration of $\mathrm{OH}-\mathrm{PCB}$ or PCBs was used as an independent variable. The concentration of individual isomer or sum of the concentrations of congeners (" $\Sigma 29$ PCB isomers" and " $\Sigma 16$ OH-PCBs isomers") was included in different models. Maternal age, maternal pre-pregnancy weight before pregnancy, parity and maternal smoking before pregnancy was included as covariates. Urinary iodine concentration was also included as an independent variable. Dietary and lifestyle factors collected by questionnaires were not included in the model because of lack of significant association between dependent variables ( $p<0.1$, one-way analysis of variance or Pearson's correlation analysis).

\section{Results}

Study population

Table 1 lists the characteristics of the subjects of this study. Although the number of subjects recruited in this study was 129, part of the information was missing for a few subjects, therefore, the number of subjects is variable depending on the item.

\section{Thyroid hormone status}

Table 2 shows concentrations of fT4, TSH and TBG in serum and that of iodine in urine taken in the first trimester of pregnancy. Although the subjects were apparently free of clinical symptoms of thyroid diseases, serum concentration of fT4, TSH and TBG for some subjects was outside the reference range. The geometric mean (GM) of urinary

Table 1 Characteristics of subjects of this study

\begin{tabular}{lrr}
\hline & $n$ & Mean \pm SD \\
\hline Age (years) & 127 & $33.8 \pm 5.0$ \\
Pre-pregnancy body weight $(\mathrm{kg})$ & 128 & $52.0 \pm 6.6$ \\
Height (cm) & 128 & $159.2 \pm 4.9$ \\
Parity (number of subjects) & 128 & \\
0 & 62 & \\
$\geq 1$ & 66 & \\
Smoking during pregnancy (number of subjects) & 127 & \\
No & 124 & \\
Yes & 3 & \\
Smoked until becoming pregnant (number of & 124 & \\
subjects) & 108 & \\
No & 16 & \\
Yes &
\end{tabular}

$S D$ standard deviation 
Table 2 Concentrations of fT4, TSH, TBG in serum and I in urine of the present subjects

\begin{tabular}{lllcr}
\hline & $n$ & Mean $(\mathrm{SD})$ & Geometric mean (GSD) & Range \\
\hline TSH $(\mu \mathrm{IU} / \mathrm{mL})$ & 129 & $1.34(1.37)$ & $0.837(3.15)$ & $0.014-10$ \\
fT4 $(\mathrm{ng} / \mathrm{dL})$ & 129 & $1.22(0.16)$ & $1.21(1.14)$ & $0.90-1.79$ \\
TBG $(\mu \mathrm{g} / \mathrm{mL})$ & 129 & $33.0(6.4)$ & $32.4(1.2)$ & $17.7-44.7$ \\
Urinary iodine $(\mu \mathrm{g} / \mathrm{g}$ creatinine) & 122 & $920(2700)$ & $370(3.0)$ & $81-27000$ \\
\hline
\end{tabular}

$S D$ standard deviation, $G S D$ geometric standard deviation

Table 3 Serum concentrations of $\Sigma \mathrm{OH}-\mathrm{PCBs}$ (pg/g wet wt.) and each isomer of the present subject $(n=128)$

\begin{tabular}{|c|c|c|c|c|c|}
\hline & \multirow[t]{2}{*}{ Percent detected $(\%)$} & \multirow[t]{2}{*}{ GM (GSD) } & \multirow[t]{2}{*}{ Median } & \multicolumn{2}{|l|}{ Range } \\
\hline & & & & Min & $\operatorname{Max}$ \\
\hline$\Sigma \mathrm{OH}-\mathrm{PCB} \_16$ isomers $(\mathrm{Pe}-\mathrm{Hp})$ & - & $120(1.7)$ & 120 & 37 & 330 \\
\hline $\mathrm{OH}-\mathrm{PeCB}$ isomer $\mathrm{A}$ & 100 & $10(1.8)$ & 11 & 1.9 & 38 \\
\hline $4^{\prime}-\mathrm{OH}-\mathrm{CB} 120$ & 96 & $1.6(1.8)$ & 1.7 & $<\mathrm{LOD}$ & 5.1 \\
\hline 3-OH-CB118 & 98 & $2.5(2.1)$ & 2.8 & $<\mathrm{LOD}$ & 11 \\
\hline 4-OH-CB107 & 100 & $24(1.7)$ & 26 & 4.8 & 95 \\
\hline $\mathrm{OH}-\mathrm{PeCB}$ isomer $\mathrm{B}$ & 100 & $3.1(1.7)$ & 3.3 & 0.8 & 8.4 \\
\hline $\mathrm{OH}-\mathrm{HxCB}$ isomer A & 100 & $4.3(1.9)$ & 4.3 & 0.6 & 21 \\
\hline 4'-OH-CB165 (3-OH-CB153) & 100 & $4.3(1.9)$ & 4.2 & 0.7 & 15 \\
\hline 4-OH-CB146 & 100 & $19(1.9)$ & 21 & 4.2 & 91 \\
\hline $3^{\prime}-\mathrm{OH}-\mathrm{CB} 138$ & 100 & $5.6(1.9)$ & 6.1 & 0.9 & 19 \\
\hline $4^{\prime}-\mathrm{OH}-\mathrm{CB} 130$ & 48 & $0.47(1.7)$ & 0.3 & $<\mathrm{LOD}$ & 1.9 \\
\hline $4^{\prime}-\mathrm{OH}-\mathrm{CB} 159$ & 88 & $1.1(2.0)$ & 1.3 & $<\mathrm{LOD}$ & 4.4 \\
\hline $\mathrm{OH}-\mathrm{HxCB}$ isomer $\mathrm{B}$ & 100 & $3.4(1.7)$ & 3.4 & 0.8 & 14 \\
\hline $\mathrm{OH}-\mathrm{HpCB}$ isomer A & 100 & $4.7(1.7)$ & 4.6 & 1.1 & 18 \\
\hline 4-OH-CB187 & 100 & $29(1.7)$ & 31 & 8.7 & 97 \\
\hline $\mathrm{OH}-\mathrm{HpCB}$ isomer B & 90 & $1.3(2.1)$ & 1.4 & $<\mathrm{LOD}$ & 5.9 \\
\hline $4^{\prime}-\mathrm{OH}-\mathrm{CB} 172$ & 100 & $3.8(1.8)$ & 3.8 & 0.9 & 16 \\
\hline
\end{tabular}

$L O D$ limit of detection, $G M$ geometric mean, GSD geometric standard deviation

GM and median values were calculated by substituting one-half of LOD for undetectable samples. One subject with low recovery of internal standard without known reason was excluded from this table

iodine concentration was $370 \mu \mathrm{g} / \mathrm{g}$ creatinine with a range $81-27000 \mu \mathrm{g} / \mathrm{g}$ creatinine.

Serum concentrations of $\mathrm{OH}-\mathrm{PCB}$ and $\mathrm{PCBs}$

Table 3 shows the concentrations of $\Sigma \mathrm{OH}-\mathrm{PCB}$ (16 isomers) and individual isomers of OH-PCB. The GM of $\Sigma \mathrm{OH}-\mathrm{PCB}$ was $120 \mathrm{pg} / \mathrm{g}$ wet wt. (range 37-330 pg/g wet wt.). $\Sigma \mathrm{OH}-\mathrm{PCBs}$ concentration increased with maternal age $(r=0.341, p<0.001)$, while it decreased with maternal pre-pregnancy weight $(r=-0.230, p=0.009)$. Mean serum $\Sigma \mathrm{OH}-\mathrm{PCB}$ concentration was higher in primiparous [GM (GSD): 160 (1.5) pg/g wet wt.] than multiparous subjects [100 (1.6) pg/g wet wt.] ( $t$ test, $p<0.001$ ) (Table 4). This significant difference was also found for the concentrations of individual isomers (data not shown). It has to be noted that there was no difference in mean age between primiparous and multiparous subjects ( $t$ test, $p=0.368$ ). Figure 1 shows the relationship between maternal age and $\Sigma \mathrm{OH}-\mathrm{PCB}$ concentration divided by parity.

Table 5 shows the concentrations of serum $\Sigma$ PCBs (29 isomers) and that of each isomer. The GM of $\Sigma$ PCBs was $68 \mathrm{ng} / \mathrm{g}$ lipid wt. (range 20-210 ng/g lipid wt.). $\Sigma$ PCBs concentration increased with maternal age $(r=0.399$, $p<0.001$ ), but it was not correlated with maternal prepregnancy weight. Mean serum PCBs concentrations were higher in the primiparous [GM (GSD): 87 (1.4) ng/g lipid wt.] than in multiparous subjects [55 (1.6) ng/g lipid wt.] ( $t$ test, $p<0.001$ ) and this difference was also significant when the individual isomer was tested except for two (CB-206, CB-209) (Table 4).

The positive correlation between the concentrations of $\mathrm{OH}-\mathrm{PCB}$ isomer and the parent $\mathrm{PCB}$ isomer was significant 
Table 4 Comparison of serum concentration of $\mathrm{OH}-\mathrm{PCB}$, PCBs and age between primiparous and multiparous subjects

\begin{tabular}{|c|c|c|c|c|c|}
\hline \multirow[b]{2}{*}{ Age (years) } & \multicolumn{2}{|c|}{ Primiparous $(n)$} & \multicolumn{2}{|c|}{ Multiparous $(n)$} & \multirow{2}{*}{$\frac{p^{*}}{0.368}$} \\
\hline & 61 & $33.4(5.6)$ & 66 & $34.2(4.4)$ & \\
\hline$\Sigma \mathrm{OH}-\mathrm{PCBs} \_16$ isomers (pg/g wet wt.) & 61 & $160(1.5)$ & 66 & $100(1.6)$ & $<0.001$ \\
\hline$\Sigma$ PCBs_29 isomers (ng/g lipid wt.) & 59 & $87(1.4)$ & 66 & $55(1.6)$ & $<0.001$ \\
\hline
\end{tabular}

Arithmetic mean and arithmetic SD for age, and geometric mean and GSD in the parenthesis for OH-PCBs and PCBs concentration

* $t$ test. Log-transformed concentration of $\mathrm{PCB}$ and $\mathrm{OH}-\mathrm{PCB}$ was used for comparison

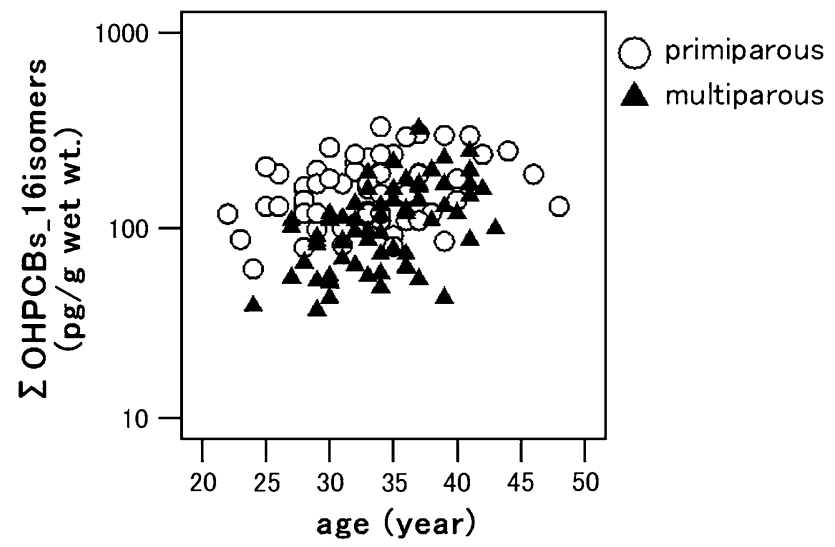

Fig. 1 Scatter plot of subject's age and serum OH-PCBs concentration (sum of 16 isomers). Correlation between age and OH-PCBs for primiparous subjects was $0.343(p=0.007)$ and that for multiparous subjects was $0.517(p<0.001)$

for all of the pairs (Table 6). Pairing of OH-PCB isomer and corresponding parent PCB isomer was determined according to Hovander et al. [26].

Association between $\mathrm{OH}-\mathrm{PCB}$ and PCBs and thyroid functions

The multiple regression analyses demonstrated that none of the independent variables included in the model (serum concentration of $\mathrm{OH}-\mathrm{PCB}$ s or PCBs with other covariates including urinary iodine concentration) significantly explain the variation of thyroid hormone status measures, i.e., serum concentration of fT4, TSH and TBG. In Table 7 is shown one such example.

\section{Discussion}

Serum concentration of $\mathrm{OH}-\mathrm{PCBs}$ and $\mathrm{PCBs}$ and their variation

The serum or plasma concentrations of $\mathrm{OH}-\mathrm{PCB}$ in the Japanese have been reported in a limited number of publications [17, 27-29]. Enomoto et al. [27] reported concentrations of six isomers of OH-PCBs in the whole blood of Japanese pregnant women (e.g., 4-OH-CB146, median $11 \mathrm{pg} / \mathrm{g}$ wet wt.). Median 4-OH-CB146 concentration in the present study ( $21 \mathrm{pg} / \mathrm{g}$ wet wt.) was in agreement with that of Enomoto et al. [27] (whole blood) if $40 \%$ hematocrit was assumed. On the other hand, the concentration was lower than that in serum of Japanese women diagnosed with breast cancer [17]. The reason for this difference may be due to the higher age of subjects $(51.1 \pm 9.8$ years $)$ in that study than that in the present study (33.8 \pm 5.0 years).

The serum concentrations of OH-PCBs in this study were generally lower than those reported in other countries $[15,30-38]$. For example, median concentration of 4-OHCB146 in the serum of Faroe Islanders (790 pg/g wet wt.) [31] was around 40 times that of this study. Elevated plasma concentrations of $\mathrm{OH}-\mathrm{PCBs}$ were also reported for Inuits [15]. The higher serum OH-PCBs concentration of Inuit and Faroe Islanders should be due to their heavy dependence on marine resources, such as sea mammals and fatty fish, which could be the source of both OH-PCBs and parent PCBs.

The concentrations of PCBs in serum were similar to those of Japanese females reported so far [40-44]. The concentrations of major PCB isomers were lower than those of studies of people who were expected to be heavily exposed for PCBs (e.g., fisherman and habitual sea mammal eaters) [15, 16, 45, 46].

Japanese people are a fish eating population, however, the serum OH-PCBs concentration was lower than those reported in the studies in Netherlands [33] or Slovakia [34] and also PCBs concentration in this study was lower than that in populations who seemingly were not heavily dependent on marine resources $[47,48]$. The reason is not clear, but exposure to PCBs/OH-PCBs via the sources other than food may have to be considered in other countries [39].

A positive correlation between age and serum $\mathrm{OH}-\mathrm{PCB}$ /PCBs concentrations, as observed in the present subjects (Fig. 1), has already been reported in previous studies $[17,49,50]$, which has been attributed to the long biological half-life of PCBs. The positive correlation found between serum concentrations of OH-PCBs and maternal age may be due to the result of metabolism of increasing body burden of parent PCBs with age. It is also well 
Table 5 Serum concentrations of $\Sigma$ PCBs and each isomer (ng/g lipid wt.) of the present subject $(n=126)$
$L O D$ limit of detection, $G M$ geometric mean, GSD geometric standard deviation GM and median values were calculated by substituting onehalf of LOD for undetectable samples. Three subjects with low recovery of internal standard were excluded from this table

\begin{tabular}{|c|c|c|c|c|c|}
\hline & \multirow[t]{2}{*}{ Percent detected $(\%)$} & \multirow[t]{2}{*}{ Geometric mean (GSD) } & \multirow[t]{2}{*}{ Median } & \multicolumn{2}{|l|}{ Range } \\
\hline & & & & Min & Max \\
\hline$\Sigma$ PCBs_29 isomers & - & $68(1.6)$ & 69 & 20 & 210 \\
\hline CB-28 & 100 & $0.68(1.6)$ & 0.63 & 0.24 & 6.7 \\
\hline CB-74 & 100 & $1.8(1.8)$ & 1.8 & 0.26 & 7.5 \\
\hline CB-66 & 100 & $0.66(1.7)$ & 0.66 & 0.17 & 4.0 \\
\hline CB-101 & 100 & $0.48(1.6)$ & 0.50 & 0.14 & 2.0 \\
\hline CB-99 & 100 & $2.4(1.7)$ & 2.6 & 0.62 & 6.5 \\
\hline CB-118 & 100 & $3.9(1.8)$ & 3.9 & 0.74 & 13 \\
\hline CB-105 & 100 & $0.80(1.7)$ & 0.84 & 0.17 & 2.4 \\
\hline CB-146 & 100 & $2.0(1.6)$ & 2.1 & 0.63 & 5.8 \\
\hline CB-153 & 100 & $16(1.7)$ & 16 & 4.2 & 54 \\
\hline CB-137 & 98 & $0.40(1.7)$ & 0.42 & $<\mathrm{LOD}$ & 1.3 \\
\hline CB-164/163 & 100 & $3.2(1.7)$ & 3.4 & 0.90 & 9.8 \\
\hline CB-138 & 100 & $8.2(1.7)$ & 8.9 & 2.2 & 28 \\
\hline CB-167 & 99 & $0.56(1.8)$ & 0.54 & $<\mathrm{LOD}$ & 2.0 \\
\hline CB-156 & 100 & $1.3(1.7)$ & 1.3 & 0.31 & 4.6 \\
\hline CB-178 & 100 & 0.84 (1.6) & 0.88 & 0.26 & 2.8 \\
\hline CB-182/187 & 100 & $4.6(1.6)$ & 4.8 & 1.6 & 13 \\
\hline CB-183 & 100 & $1.1(1.6)$ & 1.1 & 0.38 & 3.4 \\
\hline CB-177 & 100 & $0.86(1.6)$ & 0.86 & 0.28 & 2.2 \\
\hline CB-172 & 100 & $0.46(1.6)$ & 0.46 & 0.14 & 1.5 \\
\hline CB-180 & 100 & $8.6(1.6)$ & 8.6 & 2.7 & 29 \\
\hline CB-193 & 100 & $0.70(1.7)$ & 0.72 & 0.19 & 2.2 \\
\hline CB-170 & 100 & $3.0(1.6)$ & 3.0 & 0.91 & 9.3 \\
\hline CB-190 & 100 & 0.61 (1.6) & 0.61 & 0.19 & 1.8 \\
\hline OB-202 & 100 & 0.45 (1.6) & 0.44 & 0.13 & 1.7 \\
\hline OB-199 & 100 & 1.1 (1.6) & 1.1 & 0.34 & 3.6 \\
\hline OB-203 & 100 & 0.70 (1.6) & 0.71 & 0.21 & 2.2 \\
\hline OB-194 & 100 & $1.2(1.6)$ & 1.2 & 0.34 & 4.4 \\
\hline CB-206 & 99 & $0.40(1.5)$ & 0.39 & $<\mathrm{LOD}$ & 1.2 \\
\hline CB-209 & 98 & $0.33(1.6)$ & 0.32 & $<\mathrm{LOD}$ & 1.2 \\
\hline
\end{tabular}

Table 6 Correlation between the concentrations of OH-PCB isomer and the parent PCB isomer

\begin{tabular}{lllr}
\hline & Parent compound & $r^{*}$ & $p$ \\
\hline 4-OH-CB107 & CB-118+ CB-105 & 0.632 & $<0.001$ \\
4-OH-CB146 & CB-153 + CB-138 & 0.735 & $<0.001$ \\
4'-OH-CB172 & CB-170 + CB-180 & 0.711 & $<0.001$ \\
3'-OH-CB138 $^{\prime}$ LOH-PCBs_16isomers & CB-138 & 0.607 & $<0.001$ \\
\hline
\end{tabular}

* Pearson correlation coefficient. Log-transformed PCB and OH-PCB concentration was used in all analyses

documented that the body burden of PCBs of woman decreased after pregnancy and lactation [49, 51], which was also the case with the present subjects (Table 4). This has generally been attributed to "excretion" of body burden via the lactation [52]. The significant difference in serum concentration of $\mathrm{OH}-\mathrm{PCB}$ s between primiparous and multiparous subjects (Table 4) may also be due to a similar trend of parent PCBs. It must be noted that age dose not play a significant role in this difference because there was no age difference between primiparous and multiparous subjects (Table 4).

Since the biological half-time of $\mathrm{OH}-\mathrm{PCB}$ is short (3.8 days for 4-OH-CB107 and 15 days for 4-OH-CB187 in rats) [53], the observed age-dependent elevation, as well 
Table 7 An example of the result of multiple regression analysis

\begin{tabular}{llll}
\hline Dependent variable & $\mathrm{fT} 4$ & & \\
\cline { 2 - 4 } & Standardized $\beta$ & $95 \% \mathrm{CI}$ & $p$ \\
\hline$\Sigma$ OH-PCBs_16 isomers & 0.059 & $-0.046,0.078$ & 0.613 \\
Parity & -0.104 & $-0.085,0.030$ & 0.346 \\
Urinary iodine & -0.082 & $-0.033,0.014$ & 0.406 \\
Age & -0.051 & $-0.007,0.004$ & 0.406 \\
Smoking before & -0.019 & $-0.082,0.067$ & 0.841 \\
$\quad$ pregnancy & & $-0.210,0.202$ & 0.968 \\
Maternal weight & -0.004 & & \\
$\quad$ before pregnancy & & & \\
Coefficient of & & & \\
determination $\mathrm{R}^{2}$ & 0.030 & & \\
\hline
\end{tabular}

Models adjusted for maternal age, maternal weight before pregnancy, urinary I, smoking before pregnancy and parity

$\mathrm{OH}-\mathrm{PCB}$, PCBs, fT4, TSH, urinary iodine and maternal weight were log-transformed for analysis

as a significant decrease after pregnancy and lactation, in serum concentration suggested that a major portion of circulating $\mathrm{OH}-\mathrm{PCBs}$ is derived from metabolism of the parent $\mathrm{PCB}$ body burden rather than $\mathrm{OH}-\mathrm{PCB}$ s exposure.

Association between serum concentrations

of thyroid measures and $\mathrm{OH}-\mathrm{PCBs}$

The association between serum or plasma concentrations of OH-PCBs and thyroid hormone in adults has been reported in some previous studies [12, 15-17]. In none of these studies, significant association between the concentrations of OH-PCBs and fT4 in serum/plasma has been found and this was consistent with the present result. Dallaire et al. [15] reported a negative association between the concentrations of total T3 and 7 OH-PCB isomers in Inuit adults whereas they found a positive association between the sum of the concentrations of $11 \mathrm{OH}-\mathrm{PCBs}$ and T3 in another Inuit population composed of pregnant women [16]. Since T3 was not measured in this study, we do not have any idea if the serum T3 level had association with OH-PCBs in our subjects. It must be noted that in the two Dallaire et al., studies, the direction of association was inverse without known reasons. It must also be noted that the association between TBG and OH-PCBs concentration was not consistent within the two Dallaire et al., studies.

The results of several previous in vitro studies have indicated that OH-PCBs have potency for thyroid effect. $\mathrm{An}$ isomer of OH-PCB with hydroxyl group in meta or para position in its structure (e.g., 3-OH-CB118), was demonstrated to be a potent inhibitor of enzymatic sulfation of thyroid hormone in an in vitro assay [11]. Other in vitro and in vivo studies demonstrated that OH-PCBs competitively bound to transthyretin (TTR) over thyroid hormone
$[10,54,55]$. The present study, as well as some of the previous studies $[12,17]$, however, indicates that human exposure to OH-PCBs at environmental levels may not affect thyroid hormone levels in blood. It must be pointed out, however, that even if OH-PCBs affect circulating thyroid hormone by interfering binding of thyroid hormone to TTR, it may not affect the level of circulating thyroid hormone because of a minor abundance of TTR as thyroid hormone carrier protein in the blood. Therefore, although we did not see any effect on serum measures of thyroid hormones, it does not necessarily mean no effect of OH-PCBs for thyroid hormone actions.

Association of serum concentrations of thyroid measures and PCBs

It has been proposed that PCBs affect circulating thyroid hormones by (1) decreasing synthesis and secretion of T4 from the thyroid gland, (2) reducing biological half-time of T4 via the activation of UDP-glucuronosyltransferase, (3) competitively binding to carrier protein based on the findings of in vitro and in vivo studies [7, 8]. It was therefore expected that serum concentration of fT4 negatively, while that of TSH positively, correlate with the concentration of PCBs. However, we did not find any statistical associations between serum concentrations of PCBs and fT4 or TSH as in the case with OH-PCBs. Many human studies examined the association of serum measures of thyroid hormone status and PCBs and found inconsistent results. However, the majority of the previous studies found no association between the two [9] as has been found in the present study. The inconsistency across studies has generally been attributed to differences in exposure/body burden levels, measured isomers, or dietary habit and lifestyle of subject populations, across the studies. As mentioned earlier, even if serum levels of thyroid hormone do not change with PCBs exposure, it does not necessarily means that PCBs do not have any effect on thyroid actions.

Iodine as a covariate of thyroid functions

In this study we examined urinary iodine concentration as an independent variable in the multiple regression analysis. Iodine deficiency during pregnancy is associated with reduced thyroid hormone levels [56]. Meanwhile, excessive iodine intake also affects thyroid function [22, 57]. Japanese people are generally considered iodine adequate because of abundant seaweed and fish consumption: therefore, we included iodine status to see if higher (even excessive) iodine nutrition itself affects thyroid functions or it modifies the possible effect of $\mathrm{OH}-\mathrm{PCB} / \mathrm{PCBs}$ on thyroid measures. As expected, urinary iodine levels indicated that our subjects are iodine adequate or even high 
(Table 2), however, it did not contribute to variation in thyroid hormone measures. As pointed out by Dallaire et al. $[16,19]$, co-exposure to $\mathrm{OH}-\mathrm{PCB} / \mathrm{PCBs}$ and iodine takes place via the marine products consumption in general populations, therefore, $\mathrm{OH}-\mathrm{PCB}$ s and PCBs effects on thyroid functions have supposedly been investigated in iodine adequate populations as in the case with the present study. In must be noted that, except for a few studies $[20,21]$, iodine status has not been examined in the publications on PCBs and thyroid function. Effects of $\mathrm{OH}-\mathrm{PCBs} / \mathrm{PCB}$ exposure on thyroid functions under iodine less than adequate conditions may be of importance because some of the suggested mechanisms of effect of PCBs on thyroid function involved enhanced uptake of iodine into the thyroid $[58,59]$.

\section{Conclusion}

In summary, we did not find associations between $\mathrm{OH}-\mathrm{PCB}$ /PCBs exposure and thyroid hormone measures in the serum of pregnant women at first trimester of gestation in this study. This result was consistent with that of the majority of the previous studies, though not all, indicating that $\mathrm{OH}-\mathrm{PCB}$ /PCBs exposure at environmental levels does not have measurable effect on circulating thyroid hormones. However, it does not exclude the potential effect of $\mathrm{OH}-\mathrm{PCBs} / \mathrm{PCBs}$ on thyroid hormone actions in target tissues and organs without change of circulation thyroid hormone levels. It is particularly of concern for fetal exposure because the fetus is generally more vulnerable to thyroid hormone disruption than is the adult.

Acknowledgments We sincerely appreciate the subjects who participated in this study and to the technical staff and clinical staff of Showa University Hospital.

Conflict of interest The authors declare that they have no conflict of interest.

\section{References}

1. Zoeller RT, Rovet J. Timing of thyroid hormone action in the developing brain: clinical observations and experimental findings. J Neuroendocrinol. 2004;16:809-18.

2. Haddow JE, Palomaki GE, Allan WC, Williams JR, Knight GJ, Gagnon J, et al. Maternal thyroid deficiency during pregnancy and subsequent neuropsychological development of the child. N Engl J Med. 1999;341:549-55.

3. Pop VJ, Kuijpens JL, van Baar AL, Verkerk G, van Son MM, de Vijlder JJ, et al. Low maternal free thyroxine concentrations during early pregnancy are associated with impaired psychomotor development in infancy. Clin Endocrinol. 1999;50:149-55.

4. Howdeshell KL. A model of the development of the brain as a construct of the thyroid system. Environ Health Perspect. 2002;110:337-48.
5. Winneke G. Developmental aspects of environmental neurotoxicology: lessons from lead and polychlorinated biphenyls. J Neurol Sci. 2011;308:9-15.

6. Crofton KM. Thyroid disrupting chemicals: mechanisms and mixtures. Int J Androl. 2008;31:209-22.

7. Zoeller RT, Dowling ALS, Herzig CTA, Iannacone EA, Gauger KJ, Bansal R. Thyroid hormone, brain development, and the environment. Environ Health Perspect. 2002;110:355-61.

8. Hagmar L. Polychlorinated biphenyls and thyroid status in humans: a review. Thyroid. 2003;13:1021-8.

9. Salay E, Garabrant D. Polychlorinated biphenyls and thyroid hormones in adults: a systematic review appraisal of epidemiological studies. Chemosphere. 2009;74:1413-9.

10. Lans MC, Klassonwehler E, Willemsen M, Meussen E, Safe S, Brouwer A. Structure-dependent, competitive interaction of hydroxy-polychlorobiphenyls, hydroxy-dibenzo-p-dioxins and hydroxy-dibenzofurans with human transthyretin. Chem Biol Interact. 1993;88: 7-21

11. Schuur AG, Legger FF, Van Meeteren ME, Moonen MJH, Van Leeuwen-Bol I, Bergman A, et al. In vitro inhibition of thyroid hormone sulfation by hydroxylated metabolites of halogenated aromatic hydrocarbons. Chem Res Toxicol. 1998;11: $1075-81$

12. Hagmar L, Rylander L, Dyremark E, Klasson-Webler E, Erfurth EM. Plasma concentrations of persistent organochlorines in relation to thyrotropin and thyroid hormone levels in women. Int Arch Occup Environ Health. 2001;74:184-8.

13. Sandau CD, Ayotte P, Dewailly E, Duffe J, Norstrom RJ. Pentachlorophenol and hydroxylated polychlorinated biphenyl metabolites in umbilical cord plasma of neonates from coastal populations in Quebec. Environ Health Perspect. 2002;110: 411-7.

14. Otake T, Yoshinaga J, Enomoto T, Matsuda M, Wakimoto T, Ikegami $\mathrm{M}$, et al. Thyroid hormone status of newborns in relation to in utero exposure to PCBs and hydroxylated PCB metabolites. Environ Res. 2007;105:240-6.

15. Dallaire R, Dewailly E, Pereg D, Dery S, Ayotte P. Thyroid function and plasma concentrations of polyhalogenated compounds in Inuit adults. Environ Health Perspect. 2009;117: 1380-6.

16. Dallaire R, Muckle G, Dewailly E, Jacobson SW, Jacobson JL, Sandanger TM, et al. Thyroid hormone levels of pregnant Inuit women and their infants exposed to environmental contaminants. Environ Health Perspect. 2009;117:1014-20.

17. Nomiyama K, Yonehara T, Yonemura S, Yamamoto M, Koriyama $\mathrm{C}$, Akiba $\mathrm{S}$, et al. Determination and characterization of hydroxylated polychlorinated biphenyls (OH-PCBs) in serum and adipose tissue of Japanese women diagnosed with breast cancer. Environ Sci Technol. 2010;44:2890-6.

18. Delange F. The role of iodine in brain development. Proc Nutr Soc. 2000;59:75-9.

19. Dallaire R, Dewailly E, Ayotte P, Muckle G, Laliberte C, Bruneau $\mathrm{S}$. Effects of prenatal exposure to organochlorines on thyroid hormone status in newborns from two remote coastal regions in Quebec, Canada. Environ Res. 2008;108:387-92.

20. Alvarez-Pedrerol M, Guxens M, Ibarluzea J, Rebagliato M, Rodriguez A, Espada M, et al. Organochlorine compounds; Iodine intake, and thyroid hormone levels during pregnancy. Environ Sci Technol. 2009;43:7909-15.

21. Lopez-Espinosa M-J, Vizcaino E, Murcia M, Llop S, Espada M, Seco V, et al. Association between thyroid hormone levels and 4,4'-DDE concentrations in pregnant women (Valencia, Spain). Environ Res. 2009;109:479-85.

22. ICCIDD, Excessive iodine intake: a short guideline. Hans Burgi for the ICCIDD Science and Technology Committee, 2007. http://www.iccidd.org/pages/technical-resources.php. 
23. Takasuga T, Senthilkumar K, Watanabe K, Takemori H, Shoda T, Kuroda Y. Ultratrace analysis of polychlorinated biphenyls (PCBs) and their hydroxylated metabolites (HO-PCBs) in human serum and cerebrospinal fluid (CSF) samples. Organohalogen Compd. 2004;66:2501-6.

24. Akins JR, Waldrep K, Bernert JT. The estimation of total serum lipids by a completely enzymatic "summation" method. Clin Chim Acta. 1989;184:219-26.

25. Caldwell KL, Jones R, Hollowell JG. Urinary iodine concentration: United States National Health and Nutrition Examination Survey 2001-2002. Thyroid. 2005;15:692-9.

26. Hovander L, Malmberg T, Athanasiadou M, Athanassiadis L, Rahm S, Bergman A, et al. Identification of hydroxylated PCB metabolites and other phenolic halogenated pollutants in human blood plasma. Arch Environ Contam Toxicol. 2002;42:105-17.

27. Enomoto T, Nishio Y, Hasegawa J, Kato H, Miura H, Matsuda $\mathrm{M}$, et al. Hydroxylated polychlorinated biphenyl metabolites (HO-PCBs) in human blood-the concentration level in maternal blood and her umbilical cord blood, and transfer across the placenta from a mother to fetus. J Environ Chem. 2006;16:91-8 (in Japanese with English abstract).

28. Enomoto T, Nishio Y, Matsuda M, Kawano M, Wakimoto T. Hydroxylated polychlorinated biphenyl metabolites (HO-PCBs) in human blood plasma-development of analytical methods and their residue in Japanese general population. J Environ Chem. 2006;16:51-9 (in Japanese with English abstract).

29. Kawashiro Y, Fukata H, Inoue MO, Kubonoya K, Jotaki T, Takigami $\mathrm{H}$, et al. Perinatal exposure to brominated flame retardants and polychlorinated biphenyls in Japan. Endocr J. 2008;55:1071-84.

30. Fängström B, Athanasiadou M, Grandjean P, Weihe P, Bergman A. Hydroxylated PCB metabolites and PCBs in serum from pregnant Faroese women. Environ Health Perspect. 2002;110:895-9.

31. Fängström B, Hovander L, Bignert A, Athanassiadis I, Linderholm L, Grandjean P, et al. Concentrations of polyhrominated diphenyl ethers, polychlorinated biphenyls, and polychlorobiphenylols in serum from pregnant Faroese women and their children 7 years later. Environ Sci Technol. 2005;39:9457-63.

32. Guvenius DM, Aronsson A, Ekman-Ordeberg G. Bergman A, Noren K. Human prenatal and postnatal exposure to polybrominated diphenyl ethers, polychlorinated biphenyls, polychlorobiphenylols, and pentachlorophenol. Environ Health Perspect. 2003;111:1235-41.

33. Soechitram SD, Athanasiadou M, Hovander L, Bergman A, Sauer PJJ. Fetal exposure to PCBs and their hydroxylated metabolites in a Dutch cohort. Environ Health Perspect. 2004;112:1208-12.

34. Park JS, Bergman A, Linderholm L, Athanasiadou M, Kocan A, Petrik J, et al. Placental transfer of polychlorinated biphenyls, their hydroxylated metabolites and pentachlorophenol in pregnant women from eastern Slovakia. Chemosphere. 2008;70:1676-84.

35. Park JS, Petreas M, Cohn BA, Cirillo PM, Factor-Litvak P. Hydroxylated PCB metabolites (OH-PCBs) in archived serum from 1950-60 s California mothers: a pilot study. Environ Int. 2009;35:937-42.

36. Meijer L, Weiss J, Van Velzen M, Brouwer A, Bergman A, Sauerf PJJ. Serum concentrations of neutral and phenolic organohalogens in pregnant women and some of their infants in the Netherlands. Environ Sci Technol. 2008;42:3428-33.

37. Dirtu AC, Jaspers VLB, Cernat R, Neels H, Covaci A. Distribution of PCBs, their hydroxylated metabolites, and other phenolic contaminants in human serum from two European countries. Environ Sci Technol. 2010;44:2876-83.

38. Glynn A, Larsdotter M, Aune M, Darnerud PO, Bjerselius R, Bergman A. Changes in serum concentrations of polychlorinated biphenyls (PCBs), hydroxylated PCB metabolites and pentachlorophenol during pregnancy. Chemosphere. 2011;83:144-51.
39. Arisawa K, Matsumura T, Tohyama C, Saito H, Satoh H, Nagai $\mathrm{M}$, et al. Fish intake, plasma omega-3 polyunsaturated fatty acids, and polychlorinated dibenzo- $p$-dioxins/polychlorinated dibenzofurans and co-planar polychlorinated biphenyls in the blood of the Japanese population. Int Arch Occup Environ Health. 2003;76: 205-15.

40. Inoue K, Harada K, Takenaka K, Uehara S, Kono M, Shimizu T, et al. Levels and concentration ratios of polychlorinated biphenyls and polybrominated diphenyl ethers in serum and breast milk in Japanese mothers. Environ Health Perspect. 2006;114: 1179-85.

41. Tsukino H, Hanaoka T, Sasaki H, Motoyama H, Hiroshima M, Tanaka T, et al. Fish intake and serum levels of organochlorines among Japanese women. Sci Total Environ. 2006;359:90-100.

42. Nakajima S, Saijo Y, Kato S, Sasaki S, Uno K, Kanagami N, et al. Effects of prenatal exposure to polychlorinated biphenyls and dioxins on mental and motor development in Japanese children at 6 months of age. Environ Health Perspect. 2006;114: $773-8$.

43. Nakamura T, Nakai K, Matsumura T, Suzuki S, Saito Y, Satoh H. Determination of dioxins and polychlorinated biphenyls in breast milk, maternal blood and cord blood from residents of Tohoku, Japan. Sci Total Environ. 2008;394:39-51.

44. Turyk M, Anderson HA, Hanrahan LP, Falk C, Steenport DN, Needham LL, et al. Relationship of serum levels of individual PCB, dioxin, and furan congeners and DDE with Great Lakes sport-caught fish consumption. Environ Res. 2006;100:173-83.

45. Abdelouahab N, Mergler D, Takser L, Vanier C, St-Jean M, Baldwin $M$, et al. Gender differences in the effects of organochlorines, mercury, and lead on thyroid hormone levels in lakeside communities of Quebec (Canada). Environ Res. 2008;107:380-92.

46. Longnecker MP, Wolff MS, Gladen BC, Brock JW, Grandjean P, Jacobson JL, et al. Comparison of polychlorinated biphenyl levels across studies of human neurodevelopment. Environ Health Perspect. 2003;111:65-70.

47. Darnerud PO, Lignell S, Glynn A, Aune M, Tornkvist A, Stridsberg M. POP levels in breast milk and maternal serum and thyroid hormone levels in mother-child pairs from Uppsala. Sweden Environ Int. 2010;36:180-7.

48. Alcock RE, Behnisch PA, Jones KC, Hagenmaier H. Dioxin-like PCBs in the environment-human exposure and the significance of sources. Chemosphere. 1998;37:1457-72.

49. Schade G, Heinzow B. Organochlorine pesticides and polychlorinated biphenyls in human milk of mothers living in Northern Germany: current extent of contamination, time trend from 1986 to 1997 and factors that influence the levels of contamination. Sci Total Environ. 1998;215:31-9.

50. Sandau CD, Ayotte P, Dewailly E, Duffe J, Norstrom RJ. Analysis of hydroxylated metabolites of PCBs (OH-PCBs) and other chlorinated phenolic compounds in whole blood from Canadian Inuit. Environ Health Perspect. 2000;108:611-6.

51. Rylander L, Dyremark E, Stromberg U, Ostman C, Hagmar L. The impact of age, lactation and dietary habits on PCB in plasma in Swedish women. Sci Total Environ. 1997;207:55-61.

52. Rogan WJ, Gladen BC, McKinney JD, Carreras N, Hardy P, Thullen J, et al. Polychlorinated biphenyls (PCBs) and dichlorodiphenyldichloroethene (DDE) in human milk: effects of maternal factors and previous lactation. Am J Pub Health. 1986;76:172-7.

53. Malmberg T, Hoogstraate J, Bergman Å, Wehler EK. Pharmacokinetics of two major hydroxylated polychlorinated biphenyl metabolites with specific retention in rat blood. Xenobiotica. 2004;36:581-9.

54. Brouwer A, Klassonwehler E, Bokdam M, Morse DC, Traag WA. Competitive inhibition of thyroxin binding to transihyretin by 
monohy-droxy metabolites of 3,4,3',4'-tetrachlorobiphenyl. Chemosphere. 1990;20:1257-62.

55. Darnerud PO, Morse D, KlassonWehler E, Brouwer A. Binding of a $3,3^{\prime}, 4,4^{\prime}$-tetrachlorobiphenyl (CB-77) metabolite to fetal transthyretin and effects on fetal thyroid hormone levels in mice. Toxicology. 1996;106:105-14.

56. Caron P, Hoff M, Bazzi S, Dufor A, Faure G, Ghandour I, et al. Urinary iodine excretion during normal pregnancy in healthy women living in the southwest of France: correlation with maternal thyroid parameters. Thyroid. 1997;7:749-54.
57. Roti E, degli Uberti E. Iodine excess and hyperthyroidism. Thyroid. 2001;11:493-500.

58. Barter RA, Klaassen CD. Reduction of thyroid hormone levels and alteration of thyroid function by four representative UDPglucuronosyltransferase inducers in rats. Toxicol Appl Pharmacol. 1994;128:9-17.

59. Van Birgelen APJM, Smit EA, Kampen IM, Groeneveld CN, Fase KM, Van DerKolk J, et al. Subchronic effects of 2,3,7,8-TCDD or PCBs on thyroid hormone metabolism: use in risk assessment. Euro $\mathrm{J}$ Pharmacol Environ Toxicol Pharmacol Sec. 1995;5:77-85. 